\title{
Chapter 1 \\ Key Theoretical, Policy, and Implementation Experience Considerations for the Mexican ETS: Toward an Equitable and Cost-Effective Compliance Phase
}

\section{Blas L. Pérez Henríquez}

\begin{abstract}
This chapter presents a brief overview of the policy design and theoretical environmental economic principles that underpin the concept of emissions trading systems (ETS) as a policy approach to address climate change. It discusses basic environmental economic principles pertinent to the development of marketbased solutions to mitigate greenhouse gas (GHG) and co-pollutants. The chapter serves as the technical basis for the broader discussion that this book as a whole presents on the launch of the pilot phase of the Mexican ETS on January 1, 2020. Understanding international program design experiences, theoretical principles, and implementing best practices is key to ensuring Mexico's success in the transition from the pilot or learning phase to an operational ETS compliance system. This will ensure Mexico fulfills its national climate policy goals and nationally determined contributions (NDC) under the Paris Agreement in a cost-effective manner, while also providing compliance flexibility to the industrial sectors covered under the program. A well-designed ETS ultimately provides the right incentives for industrial carbon emission reductions to drive cost-effective abatement and clean innovation. Secondly, this chapter presents a more in-depth review of policy developments focusing specifically on key implementation lessons from the two most advanced ETS systems in operation to date: (1) the European Union ETS and (2) California's cap-and-trade program. In short, this chapter outlines a set of key policy lessons and design parameters to support the transition from the pilot Mexican ETS to an operational compliance phase in a socially just, environmentally sound, and cost-effective manner.
\end{abstract}

Keywords Mexico climate policy $\cdot$ Emissions trading $\cdot$ Carbon market $\cdot$ Policy design

\footnotetext{
B. L. Pérez Henríquez ( $\varangle)$

Precourt Institute for Energy, Stanford University, Stanford I Mexico Clean Economy 2050, 473 Via Ortega, Suite 324, Stanford, CA, USA

e-mail: blph@stanford.edu
} 


\section{Environmental Regulation: Conventional and Alternative Market-Based Approaches}

\section{Conventional Environmental Regulation}

The most common practice in environmental regulation is to impose a limit or quantity control on pollution, which provides certainty about the policy objective but does not create incentives to reduce total demand. This approach is also known as command-and-control regulation. This non-market approach traditionally sets a maximum allowable emissions quantity (e.g., standard) for easily identifiable point sources (e.g., smokestack). The regulator can also prescribe installing specific abatement technology (e.g., scrubbers). Because the cost of reducing emissions varies among sources, a one-size-fits-all governmental rule (or command) to control air pollution emissions, while effective, is in practice an economically inefficient approach. In addition, by picking and mandating the installation of specific cleaning technologies, regulators limit the innovation cycle and disincentivize the use of ingenuity to introduce novel production processes (i.e., clean innovation) or managerial solutions to achieve emission reductions at a lower cost to the emitter.

Direct regulations for environmental control require high levels of enforcement and inspection. The centralized standard-setting process is conducted by regulators with little knowledge of the universe of production systems on site and across industrial supply chains to be covered by the new regulation. Moreover, regulators lack information about the marginal cost of abatement for each regulated facility. Obtaining this information can be a costly and difficult endeavor for the regulatory agency, and industry has no incentive to provide it. The regulator wants to control pollution, businesses want to minimize regulatory costs. The asymmetry of information between regulated entities (e.g., production processes) and regulators' aim to reduce emissions creates a misalignment of incentives and adds costs to sharing information necessary to improve the quality of environmental protection programs (Tirole 1988, 4). Voluntary approaches, such as industry self-regulating systems, can have some positive effects but tend to be lax, inconsistent, and also require costly certification and public verification efforts to produce tangible environmental outcomes.

\section{Market-Based Environmental Policy}

An alternative policy approach to address pollution externalities is the use of market incentives (Hahn and Stavins 1992). Markets drive the efficient allocation of resources in the economy. The theoretical challenge is that there is no market for environmental resources or environmental services. There is incomplete information about prices for environmental goods. Economists would point to reasons such as non-exclusion, non-rival consumption, asymmetric information, and non-convexities 
that make assumed economic market behavior not hold as a function of supply and demand in this case (Hanley et al. 2016). Such market failures make efficient allocations of environmental services difficult to achieve. Resolving these failures has been an ongoing quest for public economic theorists.

The environmental economics paradigm calls for comparing the benefits of pollution reduction with the cost of pollution control for the regulator to set controls at the level where the marginal benefits equal the marginal costs of control (Hahn and Stavins 1992). The interdependence of ecosystems makes a full estimate of impacts elusive. In the real world, we do not have complete assessments of environmental damages, a key consideration for governance and policy design. To approximate price and make predictions, economists can elicit information through surveys to get the willingness to pay for non-market goods (i.e., contingent valuation), like a clean environment (Hanemann 1994). Prices can also be estimated through the valuation of other related goods, for instance, housing in an area with clean air, or public health expenditures (a disutility) because of air pollution, as proxy measures. These methodologies, in an indirect manner, can help economists estimate costs needed to "patch" the price system. The technological, time, and human resource requirements to consistently adapt the price to market conditions, however, makes price-setting an ongoing onerous demand on regulator resources. In short, imperfect information limits efficient outcomes. Therefore, there is a role for governmental intervention to minimize both transaction costs through careful policy design, as well as to decide on the right level of governmental supervision or control (Perez Henriquez 2013, p. 12).

Addressing global commons issues such as climate change has increasingly been on the agenda of multilateral negotiations since the mainstreaming of the concept of sustainable development at the United Nations' World Commission on Environment and Development (UNWCED) in 1987, which was aimed at avoiding compromising the natural planetary capital endowment and welfare of future generations. Crocker (1966) was the first to introduce the idea of using a market to address atmospheric pollution control systems. In 1997, the United Nations Conference on Trade and Development (UNCTAD) launched the GHG Emissions Trading Policy Forum. At the inaugural multi-stakeholder event, Maurice Strong, Chairman of the Earth Council and Secretary-General of the 1992 Earth Summit, argued that "an international market for greenhouse gases bridges the gap between the environmental objective of lowering emissions and industry's need for flexible, economical paths for achieving this objective, while encouraging new investments in sustainable development" (UNCTAD 1997). These discussions jumpstarted the debate on the use of emissions trading as a policy approach within the United Nations climate negotiations process. Comparing alternative institutional arrangements or policy approaches is key to evaluating options and achieving policy outcomes in a more efficient manner. Distributional equity is an important criterion that cannot be dismissed, particularly in the context of international climate policy (Baumol and Oates 1988). 


\section{Carbon Pricing, Markets, and Innovation}

There is a high degree of certainty and consensus among the international scientific community that the heat-trapping effect of GHG emissions (or carbon) accumulation in the atmosphere due to human activities over the last 150 years is the main cause of global warming, threatening biodiversity and human existence. A price on carbon is the most practical policy solution to decarbonize our global economy. Whether through taxes (Pigou 1932) or cap-and-trade programs (Coase 1960; Dales 1968), a price on carbon transfers the social cost of climate change to emitters and requires them to choose how to address this cost. It therefore promotes emission reductions and investment in smart, clean energy solutions and low-carbon economic development. In the real world, policy analysts must consider how market-based policy instruments are constrained by political, administrative, and other institutional factors, as well as by self-interested actors (Pérez Henríquez 2013).

As suggested by Nordhaus (2017), the social cost of carbon (SCC) is a central concept for understanding and implementing climate change policies. The SCC is the monetary value of environmental damage from emitting an additional ton of carbon into the atmosphere. Avoiding these negative impacts on the economic welfare of nations makes carbon mitigation and adaptation investments worthwhile. For example, if you are a country highly vulnerable to climate stressors and risk as in the case of Mexico, water scarcity in surface and groundwater recharge from extended droughts along with reduced hydropower generation could negatively impact the delicate water-energy-food nexus balance of these interdependent shared-resource systems. Further, hurricanes and superstorms are expected to affect critical infrastructure (e.g., power stations and dams), disrupting housing, physical and electronic communications, as well as supply chains and economic activity in general due to more frequent, damaging, and costly extreme weather events (United States Agency for International Development 2017).

As noted in Burke et al. (2016), researchers have dramatically advanced our understanding of the physical science of climate change. Implications of this knowledge for society remain limited, but some progress has been achieved in formalizing climate-economy linkages. Refining the SCC and enhancing our capacity to assess the economic impacts of alternative policy approaches, in particular for developing countries, are current topics in the environmental economics research agenda. Emitting one unit of carbon, in a city, industrial park, or by wildfires, contributes the same to climate change regardless of where it is emitted. Consequently, the social damage caused is the same. Stern (2007) provoked a debate on how best to estimate the benefits of carbon emission mitigation in order to avoid costly climatic effects in the future. Dietz and Stern (2008) later emphasized that adaptation investment strategies play a key role in minimizing the costs and maximizing the benefits of planetary warming. Both carbon pricing mechanisms as described below create a new source of revenue for governments. The revenue raised can reduce the social cost of these programs, for instance, by eliminating distortionary taxes (Goulder 1995). However, the use of revenue may be controversial and politically contentious 
because of its potential impact on the overall cost of market-based approaches and their distributional effects. Revenue can go, for instance, to the general government treasury, or support environmental and social remediation, or climate investment and low-carbon development initiatives and adaptation projects.

Despite calls for urgent climate action from scientists, environmental groups, and young voices of the next generation, the Paris Agreement mitigation and climate action plans need enhanced ambition and are behind schedule to stabilize emissions and avoid catastrophic warming by the end of this century. Moreover, the levels of climate investment funds necessary for a transition to a global clean economy, are not readily available. While in the short term, policy makers can reap low-hanging fruit benefits from stated governmental mitigation programs (i.e., NDCs) and supplementary actions, long-term goals of transitioning to a net-zero carbon future by 2050 will require deeper, more costly carbon emission reductions. Some industrial sectors have a heavier lift ahead in their decarbonization process (e.g., hydrocarbon industry, cement, steel, and aluminum). Fossil fuel use continues to grow at the global level, in particular in large developing countries, including Mexico. To effectively address this situation, scientists and expert research groups tracking global carbon emissions such as the Global Carbon Project state that "we need accelerated energy efficiency improvements and reduced consumption, rapid deployment of electric vehicles, carbon capture and storage technologies, and a decarbonized electricity grid, with new renewable capacities replacing fossil fuels, not supplementing them. Stronger global commitments and carbon pricing would help implement such policies at scale and in time" (Jackson et al. 2019). Moreover, climate investment in innovative carbon management technologies can provide cost-effective solutions in the long run (Gillingham 2019).

Experience shows that meaningful carbon prices create a strong business incentive to invest in low-carbon technology and clean innovation. As reported by the World Economic Forum (2017) based on the European carbon market experience, at certain carbon price levels, companies will file more patents in the new clean economy sectors described above. Recent policy fine-tuning of the EU ETS is delivering enhanced incentives for innovation and adoption of low-carbon technologies (Teixidó et al. 2019). Accelerating and de-risking deployment is central to this process. How we choosing to control carbon is key to achieve the desired policy outcomes (Goulder and Parry 2008). Theoretically, under a full-information scenario, tradable allowances (or quotas) and taxes are equivalent regulatory instruments (Montgomery 1972; Weitzman 1974). However, as established above, this is not the case in practice given the uncertain level of environmental damages. Hybrid policy designs with overlapping policies may be appropriate for cost-effective and equitable climate action, but this requires a high degree of regulatory coordination by government (Pérez Henríquez 2013).

The two main carbon pricing mechanisms are as follows. 


\section{Carbon Tax}

From the environmental policy implementation perspective, the key aspect of a carbon tax is that it provides price certainty to regulated entities. This is why this approach is generally preferred by industry. A carbon tax creates a uniform price on emissions irrespective of the source. This allows the cost to regulated entities of reducing their emissions by one unit at the margin as defined by economists to be equalized across all facilities and sectors of the economy, thus making it technically appealing (Pizer 1999; Nordhaus 2005).

However, a significant concern, particularly for some environmental groups, is that there is no certainty on the amount of emissions reduced in a certain period. While considered by many a straightforward proposition, the technically elegant global carbon tax has also not yet passed the political feasibility test across most national and regional policy processes around the world. Passing a new, significant green tax is a tough sell for any politician. As reported by The Guardian, the French government's ongoing experience with the Gilets Jaunes or "yellow vests" movement against ecotaxes in the transportation sector, with support of $70 \%$ of the general population, illustrates this point (Willsher 2018). This is despite France's strong support for the Paris Agreement, its own "ecological transition" national objectives, and its overall global leadership on climate policy. In Europe, in general, "pollution and resource taxes account for a very small portion of the tax revenue" vis-à-vis energy taxes (Willsher 2018). Instead of a carbon tax, therefore, an ETS was the system that the European Union adopted to address GHG emission reductions.

Likewise, several carbon legislation proposals have been in wait to survive the policy process in the United States Congress, but without much potential to become federal policy. However, the significant federal revenue-raising potential from a carbon tax is often cited as an incentive to decisionmakers to favor the passing of carbon tax legislation. This may become a salient political feasibility consideration, particularly in the face of the potential budgetary shortfalls that the Covid19 public health crisis may create across all levels of government in the near future.

\section{Emissions Trading Systems}

The key policy aspect of implementing a cap-and-trade approach is that it establishes a clear environmental goal. This type of ETS ideally sets a science-based limit, but in practice, a politically agreed-upon maximum allowable limit on emissions from all program participants by a central agent (i.e., regulator), and grants flexibility to program participants to search for the most cost-effective emission reductions through investments in pollution removal systems, technological innovation, or by applying managerial ingenuity to mitigate emissions. Some environmental groups tend to favor this approach because it focuses on achieving a clearly defined environmental policy objective (i.e., the cap). 
In a cap-and-trade ETS, regulated entities are required to meet a universal target (or cap) on all emissions in the economy or in a specific sector (e.g., electricity generation), but without directly prescribing how to achieve the emission reductions (Tietenberg 2005, 2006). Emission permits or allowances (quasi-legal property rights) based on the total cap are allocated among participants (or purchased through annual auctions). Those who can reduce emissions in the most cost-effective manner will have a surplus of emission credits to sell in such an environmental commodity market. Those with relatively more expensive mitigation costs will have to buy a number of permits needed to meet their annual quota and compensate for added pollution. Cost minimization opportunities in a market-based system arise as the differences in the cost of pollution abatement across sources increases (Newell and Stavins 2003). GHG sources are diverse and heterogeneous. Thus, heterogeneity and market scale determine the amount of such opportunities, while the system's gains in economic efficiency are enhanced as the size of the ETS expands, particularly across jurisdictions regionally or at a global level.

Approaches focused on setting maximum caps on targeted emissions with allowance trading provide incentives to mitigate emissions per unit of production output. The theoretical promise is that these policy approaches are relatively costeffective to both the regulator and the emitter. Prices are not set by the regulator beyond potential floors and ceilings, but are determined by the relationship between the supply of excess emission credits from those entities that emit less than the cap, and the demand for credits from those entities that have not met their caps. The financial and technical context of each regulated entity determines whether they decide to invest in improved emission controls, fostering technological innovation and novel managerial approaches, or in purchasing excess emission allowances from those entities that have exceeded their requirements.

From the perspective of the environmental administrator, theoretically, this frees the public regulator from having to track and analyze all of this exchange data. The necessary caveats to this approach, however, include the need to pay close attention to distribution changes in the policy's environmental benefits, as it can potentially exacerbate existing public health disparities if the heaviest polluters decide to purchase credits instead of reducing emissions when they are located in already overpolluted areas. Additionally, the market has to be closely monitored for manipulation, particularly if the underlying regulated entities are part of a sector with monopolistic characteristics (electricity distribution, etc.). However, modern information and communication technologies, through sensors, mobile monitoring, continuous emission monitoring systems (CEMS), and online operation tracking, reduce administrative and transactional costs in the implementation and oversight of environmental commodity markets (Pérez Henríquez 2004).

More than 30 years of implementation experience with cap-and-trade programs offers a wealth of lessons on how economic efficiency was gradually achieved through policy design improvement and fine-tuning. This experience has also been informing the process of developing new ETS programs around the world to address climate change (Schmalensee and Stavins 2017). However, a smart policy approach can easily become inefficient and ineffective if its design and implementation processes 
are compromised or if it lacks the flexibility to iteratively adapt to evolving political, economic, environmental, and social conditions. Political concessions during the policy process and exogenous factors can diminish the economic efficiency of an ETS (Perez Henriquez 2013).

There are several lessons from this implementation history with cap-and-trade systems that are key to the future success of growing carbon markets and emerging ETS policies.

Cap: Perhaps the most significant lesson to date is the importance of establishing a well-defined, transparent, and sufficiently strict initial emissions cap. Such a cap will ensure both the environmental and market credibility of the program and, through scarcity, trigger the necessary demand for emission credits to foster an emissions market. Accurate ex ante emission data is required to establish a cap that is stringent enough to produce scarcity in the market at the start (with the expectation of increasing ambition as needed in the future).

Carbon pricing and policy continuity: A meaningful allowance price (and/or price floor), along with a credible government commitment to long-term carbon market policy continuity toward a zero-emission future, creates confidence in the effectiveness and legal certainty of emissions trading markets.

Allocation: (1) Direct: Allowance distribution is provided directly to regulated entities, utility rate payers, and other special sectors to smooth the transition to a lowcarbon economy, as well as to minimize emission leakage (i.e., emission increases outside of the ETS-covered industry or jurisdiction) while maintaining local production. Free allowance allocations enhance the political feasibility of the program at the onset and support economic development and competitiveness. (2) Auctions: Alternatively, auction sales for all market participants provide access to allowances. Emission auctions jumpstart the market through price signals. They also provide new industry entrants with allowances and allow ETS participants in general to buy permits as they plan ahead in balancing their production goal with environmental compliance.

Climate investment: As mentioned above, carbon pricing can also provide revenue for climate investment (e.g., allowance auctions, carbon price floors, and carbon taxes), foster low-carbon development, or provide direct dividends to society from the decarbonization effort.

Cost Containment and Competitiveness: Cost containment measures such as credits outside the cap (e.g., carbon offsets from an array of approved projects), as well as price caps and allowance reserves for market stabilization, can also provide flexibility and price certainty to maintain jurisdictional economic competitiveness during the decarbonization process.

Penalties: Meaningful penalties for failure to meet annual emission reduction goals - through emission reduction or purchase of allowances-are also key to making the system effective.

Emission clustering and environmental justice: Air pollutants produced along with GHGs from hydrocarbon combustion frequently result in illness and environmental hazards to communities living in urban areas, near industrial facilities, or transport hubs like port facilities. Localized emissions (or hotspots) exacerbate asthma and 
morbidity rates among at-risk populations and, in most cases, in economically and socially disadvantaged areas. Thus, climate action plans that strongly link marketbased carbon mitigation with air pollution protection from co-pollutants will have more equitable, just outcomes.

\section{Creating Global Environmental Commodity Markets}

The use of carbon pricing policy by governments around the world is increasing as a means to address climate change by stabilizing GHG emissions in a costeffective manner and limiting global temperature rise to below $2{ }^{\circ} \mathrm{C}$ within this century. The World Bank (2020) has developed a Carbon Pricing Dashboard which reports that, to date, 61 regional, national, and subnational programs (e.g., carbon tax, ETS, and hybrid systems) are operating or scheduled for implementation globally. These carbon pricing initiatives include 46 national and 32 subnational jurisdictional mitigation efforts, representing about $22.3 \%$ of global GHG emissions in 2020. The European Union ETS and the California cap-and-trade carbon market operating jointly with the Canadian province of Quebec as part of the Western Climate Initiative represent a collaborative effort toward a future North American ETS. Both regional carbon trading programs represent the state-of-the-art design and implementation of this market-based policy approach. However, important developments in other regions are in place, including ETS programs launched in China in 2017, South Korea in 2015, and Kazakhstan in 2013, representing key Asian developments toward a future global carbon market.

It is true that many countries, subnational governments, and regions around the world have introduced cap-and-trade emission trading systems to mitigate carbon emissions. However, as attested by the negotiations under the United Nations Climate Framework Convention on Change Climate (UNFCCC) Paris Agreement over Article 6 , at the multilateral level, the idea of establishing a global carbon market remains contentious. Even the use of the word "market" is questioned by some stakeholders. Some environmental organizations still consider it unethical to "trade" environmental goods or to use the natural capital of indigenous communities to compensate for emissions from large industrial emitters. Other civil society and non-governmental groups, think tanks, and advocates who see the benefits of carbon pricing as a policy tool want assurances that a future global carbon market will avoid double-counting (e.g., NDC goals vs. an international offset program), forbid carryovers of units derived from older systems such as the Kyoto Protocol, and demand the inclusion of more holistic social and environmental safeguards that protect human rights, ensure effective mitigation of global emissions, and achieve sustainable development goals (SDGs) (Climate Action Network 2019). Industry lobbies want to ensure the minimization of compliance costs and achieve overall climate goals in a more efficient manner. The savings potential in the implementation of NDCs could reach $\sim 250$ billion per year in 2030, or alternatively "facilitate the removal of 50 percent more emissions ( $\sim \mathrm{GtCO}_{2}$ per year), at no additional cost” (Edmonds et al. 2019). All this 
is contingent on the implementation of a well-designed, operational global carbon market.

UN diplomatic negotiations over Article 6 have agreed on terms such as "cooperative approaches" to develop internationally transferred mitigation outcomes (ITMOS) in order to avoid using the term "carbon market". Under these future rules, countries would allow the exchange of ITMOS and linkages among systems. Decisions on setting the rules for such a system at the multilateral level are highly contentious. Heterogeneity in policy objectives and approaches among national, regional, and local governments and their interaction with the NDC system has become a hurdle to advancing rules and aspects of implementation. Demonstrating that credible and technically sound convergence in accounting, environmental integrity, and transparency policy design features is feasible between different national approaches among treaty signatories can be the first step. Such experiences can provide valuable implementation lessons that can serve as trust-building foundations to support cost-effective global collective climate action while at the same time providing policy design protocols for others to formally join these efforts. A well-functioning global carbon market could allow for cost-savings to be invested in the transition to a clean economy and to foster low-carbon development around the world.

According to the International Carbon Action Partnership (ICAP) in its most recent report on ETS developments around the world (2020), one-sixth of the global population lives under an ETS. These jurisdictions represent $42 \%$ of global gross domestic product (GDP) — up from 37\% a year ago — and the systems cover 9\% of GHG emissions worldwide. By 2021, ICAP estimates that $14 \%$ of global emissions will come under an ETS as more systems come online, including China. Launched in 2017, the China ETS will be approximately twice the size of the EU ETS and almost nine times the size of the California cap-and-trade system making it the largest in the world (Stavins 2018). Carbon market implementation lessons will soon emerge from Asian manufacturing and export-oriented peers to Mexico. However, at this time, the two most pertinent experiences to date that can inform Mexico's ETS implementation process are the European Union (EU) ETS and the California experience.

\section{EU ETS}

The first full-fledged multi-national ETS developed to address climate change in the world was the European Union ETS. In tandem with a series of supplementary measures and programs, this cap-and-trade system was introduced by the EU Commission as its main policy for GHG mitigation in the region. It covers approximately $45 \%$ of EU emissions from the power, industrial, and internal aviation sectors. More recently, the European Green Deal has set an ambitious goal for EU members to become climate neutral by 2050. For instance, it aims to reach clean energy and energy efficiency levels of 32 and $32.5 \%$, respectively, by 2030, and periodically revises these goals upwards. An important effort to strengthen the EU ETS is to 
improve the integration of monitoring, reporting, and verification (MRV) rules to meet its own policy objectives and international commitments under the Paris Agreement. The EU ETS is entering into its fourth phase and implementing its most recent fine-tuning adjustment. Unfortunately, the UK, where the program was first piloted for the benefit of the EU, formally retired from this association in 2019. There is some market uncertainty triggered by this process. However, in January 2020, the EU ETS successfully linked up with the Swiss carbon market.

As noted above, the EU ETS is not an economy-wide cap-and-trade system. It has been gradually implemented, under a sector-based approach focusing on already highly regulated, energy-intensive sectors such as electric power generators and large, stationary industrial sources. Coverage has been expanding throughout the years. Initially, it allowed member nations to develop internal capacities and inform the system independently. However, the EU experience demonstrates the importance of a central coordinating agent that ensures the environmental integrity of the system.

Launched in 2005, the EU ETS has faced some significant learning experiences such as over-allocation of allowances and exogenous shocks such as the deacceleration of the economy due to the 2008 financial crisis. As a result of over-allocation and reduced demand, the EU ETS found it necessary to introduce a cap adjustment to trigger some scarcity of allowances in the market through a policy known as backloading. This temporarily reduced the auction volumes during the 2014-2016 period. The amount of reduced allowances ( 900 million total) was reintroduced into the system in 2019 and 2020. This caused price instability and some strategic market speculation with these environmental commodities. There was also an oversupply of offsets, which forced the EU to close the door to such cost-containment instruments, de facto halting the clean development mechanism process. The size of the EU ETS and insufficient cybersecurity for emissions registries produced large fraud and tax avoidance schemes. After adapting to these challenges through fine-tuning and learning by doing, the EU ETS has managed to gain some relative price stability while helping to decarbonize the EU region.

Phase IV of the EU ETS is currently setting the new market rules for the next decade (i.e., post 2020). According to the European Commission (2017), in order "to achieve the EU's overall greenhouse gas emissions reduction target for 2030, the sectors covered by the EU Emissions Trading System (EU ETS) must reduce their emissions by $43 \%$ compared to 2005 levels. The revised EU ETS Directive, which will apply for the 2021-2030 period, will enable this through a mix of interlinked measures." Below is a summary of key adjustments to the program:

Adjusting the Cap: A key factor signaling to market participants that there will be gradual reductions in the availability of allowances is the "Linear Reduction Factor (LRF)" that adjusts the EU ETS cap starting in 2021 to a $2.2 \%$ annual decrease in total allowances from the previous $1.74 \%$. This gradual cap reduction will result in $43 \%$ fewer allowances available in the market by 2030 compared to the start of the program in 2005. Free allocations will now target emission intensity improvement over absolute mitigation, and will have a schedule of two allocation periods-2021-2025 and 2026-2030. Allocations will be based on 
real data in the process of collection using a benchmarking system set by the $10 \%$ best-performing facilities in each sector. A new measure to avoid over-allocation is to provide more flexibility in addressing capacity changes or activity levels, stopping operations, mergers and acquisitions, etc. based on a certain percentage of reduced or increased operations to determine free allocation adjustments.

Market Stability Reserve (MSR): The EU established the MSR to reduce the surplus of emission allowances in the system and improve EU ETS resilience to future market shocks. To strengthen its function, "between 2019 and 2023, the amount of allowances put in the reserve will double to $24 \%$ of the allowances in circulation. The regular feeding rate of $12 \%$ will be restored as of 2024 . As a longterm measure to improve the functioning of the EU ETS, and unless otherwise decided in the first review of the MSR in 2021, from 2023 onwards the number of allowances held in the reserve will be limited to the auction volume of the previous year. Holdings above that amount will lose their validity." (European Commission, 2017)

Carbon Leakage Risk: The system of free allocation will be prolonged for another decade and has been revised to focus on sectors at the highest risk of relocating their production outside of the EU. These sectors will receive $100 \%$ of their allocation for free. For less-exposed sectors, free allocation is foreseen to be phased out after 2026 from a maximum of $30 \%$ to 0 at the end of phase 4 (2030). A considerable number of free allowances will be set aside for new and growing installations. This number consists of allowances that were not allocated from the total amount available for free allocation by the end of phase 3 (2020) and 200 million allowances from the MSR. A series of additional flexibility rules aim to better align the free allocation process with actual production levels while minimizing carbon leakage risk.

Climate Investment: The EU ETS has decided to fund directly from their auctions in order to "de-risk" innovation projects and accelerate decarbonization in the region while supporting research to market projects. Through the Innovation Fund, the EU will fund demonstration projects of cutting-edge technology both on a large and small scales. This could include novel clean energy systems, energy storage, and a boost to carbon capturing, utilization, and storage projects. The EU ETS revenue will also provide for a modernization fund that will provide additional funding to continued efforts to modernize energy system transformation in the 10 lowest income EU members. No funding will be directed to coal-fired electric generation and minimal finance will be provided to improve natural gas power plants.

Offsets: Offsets will continue to be prohibited under Phase IV to maintain a strict cap on regional emissions. However, the EU Commission has signaled that once an agreement on Article 6 of the Paris Agreement is reached, ITMOs will be part of the system. No Kyoto offset instruments will be allowed in the EU ETS beyond 2030 .

Perhaps the most important lesson from the implementation of the EU ETS is that addressing the climate challenge requires an array of policies and measures 
(Delbeke and Vis 2019). However, overlapping policies can impact the environmental and economic performance of these programs. An ETS relies on the market to identify the least-cost carbon mitigation opportunities. Complementary policies can disrupt these market incentives. Careful policy design, implementation, and review to balance policy objectives and other co-benefits are required. The tradeoffs between policies and objectives need to continuously be reviewed to improve the overall cost-effectiveness, environmental integrity, and equitable implementation of the program toward a carbon-neutral economy. This is particularly relevant in the face of global trends toward deep decarbonization efforts to achieve net-zero emission transformation of key economic sectors such as energy and transport systems.

\section{North American Developments}

In North America, California and Quebec have taken the lead implementing ETS programs, and developing workable linking protocols for both parties. Both subnational jurisdictions see the electrification of the economy as a key infrastructure transformation challenge that, when supported by clean innovation solutions, will enable a net-zero carbon future. Quebec is strengthening its institutional setup around climate by creating a climate change advisory committee and restructuring its climate investment program through a revamped Green Fund. Both subnational jurisdictions have energy sectors with a high supply of renewable power.

Political cycles have affected the level of support for carbon pricing policy in North America. Both the US and Canada have been in and out of the UNFCCC climate process. Canada withdrew from the Kyoto Protocol in December 2012 but is now an active member of the Paris Agreement. Under the Trudeau premiership, Canada returned to action, introducing a national carbon price floor and allowing provinces to choose their own policy approach to meet Canada's climate objectives. Under the Canadian federal backstop system, provincial governments can opt between (1) An output-based pricing system and (2) A carbon levy (or tax). This applies to provinces and territories having no carbon pricing systems validated by the central government in place. In 2016, this pan-Canadian carbon pricing system was introduced and set a minimum price of CAN \$10 per ton of carbon in 2018, increasing to CAN \$50 in 2022. Alternatively, provinces may choose option 1 and establish an equivalently scaled ETS. Experts believe welfare and implementation costs are "manageable" and the system will create an important source of revenue (Parry and Mylonas 2017). Carbon pricing in Canada has been an evolutionary process. For instance, since 2008 British Columbia has demonstrated that it can use a neutral carbon tax, granting carbon rebates and spurring energy-efficient processes without slowing down economic performance. The principle of neutrality applies to the revenue raised from the central backstop system, as it is designed to be returned to those sectors and households that paid the charge. On the other hand, as mentioned above, elections matter. At one point, Ontario was in line to link with California and Quebec's carbon market, but a political cycle canceled that process on July 3, 2018, as a conservative government opposing 
the policy got elected. Constitutional challenges by some provinces resisting the implementation of the backstop system are being litigated in courts.

In the United States, climate action is being mostly led by local governments and communities around the country. Under the Obama administration, much support was given to global climate action. However, meaningful federal climate laws to support executive actions (e.g., Clean Power Plan) have been dismantled by the Trump administration. Delivering on a campaign promise, on January 1, 2017, the Trump administration announced it would withdraw from the Paris Agreement.

In the case of Mexico, its government has been an active participant in the UNFCCC process. As host of the COP13 in Cancun, its diplomatic skill and political leadership at that summit were key to boosting the weakened multilateral process. A member of the OECD and the G20 multi-national groupings, it has historically had access to and participates in high-level discussions about how to best address climate change while advancing its sustainable development objectives. In 2012, Mexico became the first developing country, and second in the world after the United Kingdom, to pass a federal climate bill - the General Law of Climate Change (LGCC). Also, in 2014, it passed a carbon tax at a very low level on fossil fuels with the intention of raising awareness on carbon emissions, but with limited effect on emission reductions. However, this prompted the debate around the use of compensatory measures through emission offsets, mainly by the private sector. In January 2020, the pilot phase of the Mexican ETS was launched. If fully implemented, it will become the only federal ETS in North America, and the first national cap-andtrade system in the Americas. This process occurs at the start of a new presidential administration with a different perspective in terms of decarbonization, and with new directions for the energy sector that emphasize hydrocarbons, which will make the implementation of Mexico's climate action plan challenging.

\section{California}

Climate risk is a reality for all Californians. Like Mexico, California is highly vulnerable to global warming and its economic impacts as demonstrated by recent periods of long-term droughts, followed by superstorms and destructive firestorms. California is recognized as a global subnational leader in climate action contributing to the global efforts under the Paris Agreement. In 2006, the trailblazing Global Warming Solutions Act or AB32 was passed into law. While not a country party to the UNFCCC process, California represents the fifth largest economy in the world. Californians have been able to sustain economic growth while becoming less carbon-intensive, as seen in Fig. 1.1 below. This has demonstrated that clean tech innovation can be an engine for economic growth while transitioning to a smarter, inclusive, resilient, and cleaner economic development model.

With no climate policy coming out of Washington, DC, the State has taken the lead on climate action in the United States. This has not occurred without contention 


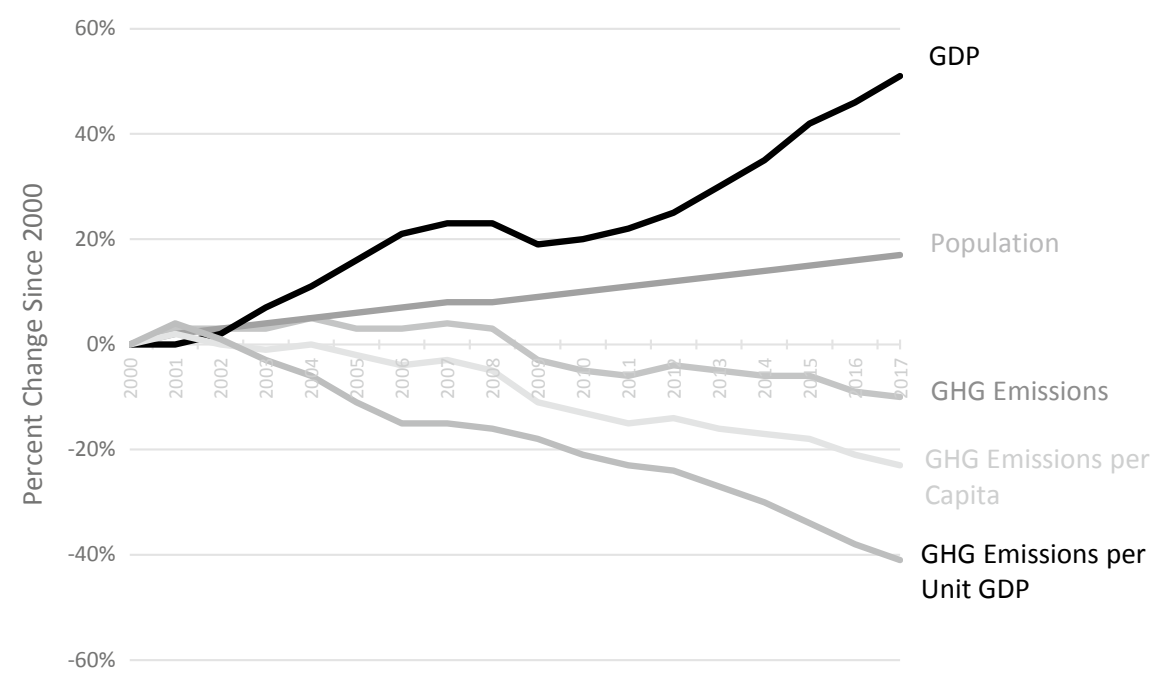

Fig. 1.1 Decoupled GHG emissions, GDP, and population trends in California from 2000 to 2017. Data from CARB (2019)

in recent years. While in the past, California had been the darling of federal environmental policy makers, winning regulatory exceptions based on its record of developing innovative environmental programs, more recently the state has been challenged by the Trump administration. Trump's administration has sued California because of its international cooperation with the Canadian province of Quebec in linking carbon markets, as well as for de facto setting national fuel efficiency standards to vehicles, among many other legal disputes. Under the Trump administration, as summarized by National Geographic, there has been an unwinding of important federal environmental regulations across the board to reduce regulation and control regulatory costs (Gibbens 2019).

AB 32 initially set a GHG emission target to reduce emissions to 1990 levels by 2020. California surpassed its 2020 climate targets in 2016 (see Fig. 1.4 below), while the economy continues to grow. Through its Climate Change Scoping Plan, the state periodically outlines and updates a series of programs and policies to decarbonize its economy and move toward a clean economy. These include reducing the carbon footprint of the state through carbon pricing, resource efficiency, and the deployment of clean energy and sustainable transport solutions. This portfolio approach aims both at addressing global climate change and state adaptation needs, while also ensuring that all Californians are able to enjoy their rights to clean air, clean water, and a healthy and safe environment.

Among the most innovative sectoral programs implemented in California to become a resource-efficient, clean, and climate responsible economy are the following. 


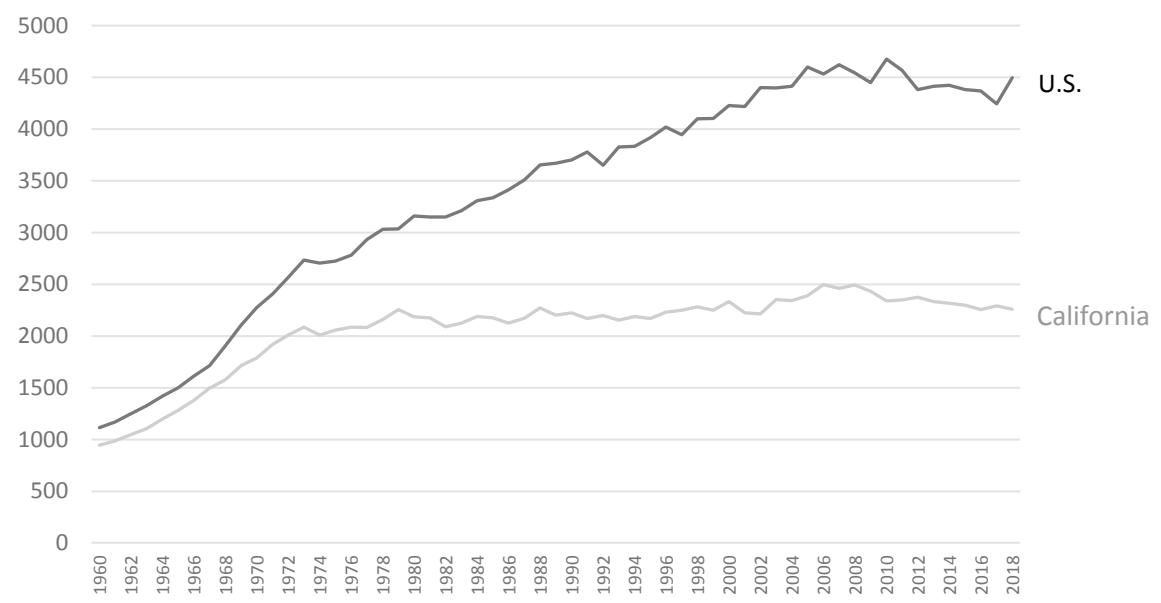

Fig. 1.2 U.S. and California per capita residential electricity consumption 1960-2018. Data from U.S. Energy Information Administration State Energy Data System (2020a)

\section{Energy efficiency standards}

California launched Appliance Energy Efficiency Standards in 1977 and the Building Energy Efficiency Standards in 1978 in part to respond to the energy crisis of the 1970s. These standards have been credited as a significant reason why California was able to delink its continued economic growth from growth in energy demand, although rising fossil fuel prices from 1973 to 1981 likely triggered efficiency innovation beyond regulatory requirements. Figure 1.2 below shows how California has been able to become an energy resource-efficient economy vis-à-vis the United States in general.

\section{Renewable portfolio standards (RPS)}

California instituted an RPS in 2002 under Senate Bill 1078 with the original aim of sourcing $20 \%$ of retail electricity sold from renewable sources by 2017 . This was increased to 50\% of electricity sales by 2030 under SB 250 in 2015 . SB 100, signed into law in 2018, increased this requirement to $60 \%$ by 2030 and $100 \%$ by 2045 and specified the renewable sources must be carbon-free. By 2017, a majority of retail sellers of electricity had met or exceeded their updated interim 2017 target of $27 \%$ renewable sourcing (Figs. 1.3, 1.4).

\section{Low-carbon fuel standards (LCFS)}

In 2002, with the implementation of AB 1493, known as the Pavley Regulations, California instituted corporate average fuel economy standards stricter than those of the U.S. EPA. After an extended battle with automakers and trade associations, and eventually negotiations between California, the federal government and automakers, the EPA granted California a pre-emption waiver under the Federal Clean Air Act in 2009, which would allow California to set higher standards. Because California is 
1 Key Theoretical, Policy, and Implementation Experience ...

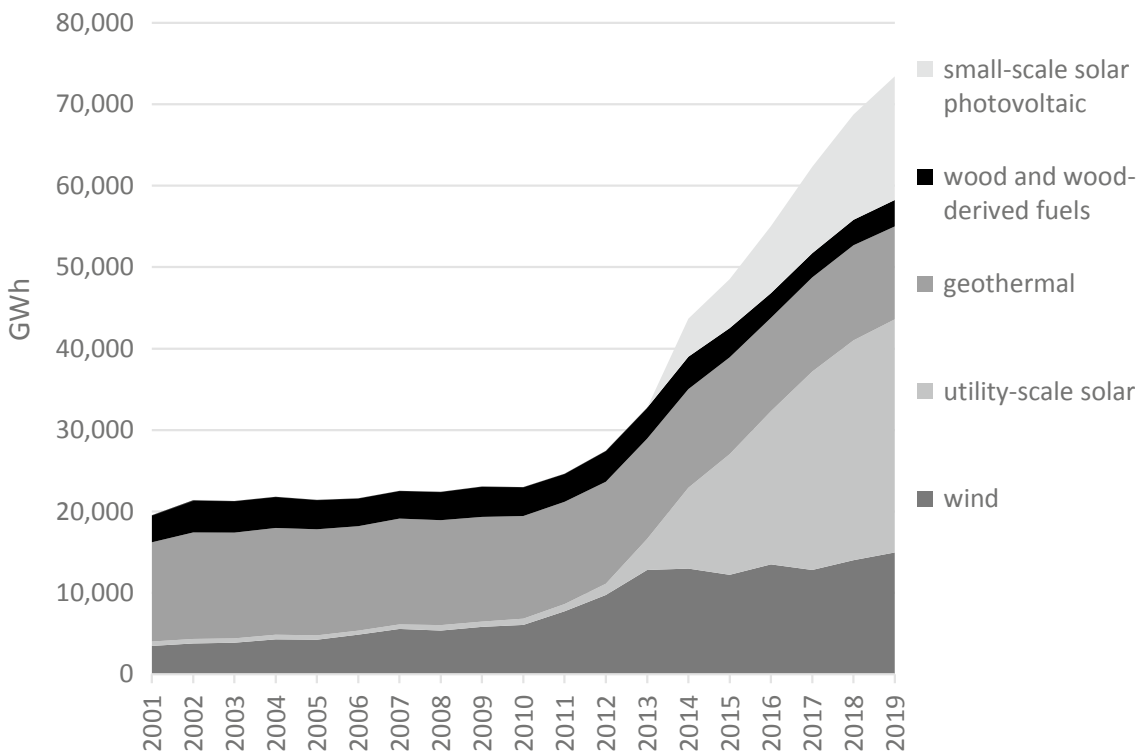

Fig. 1.3 Renewable electricity generation in California by resource type. Data from USEIA (2020b)

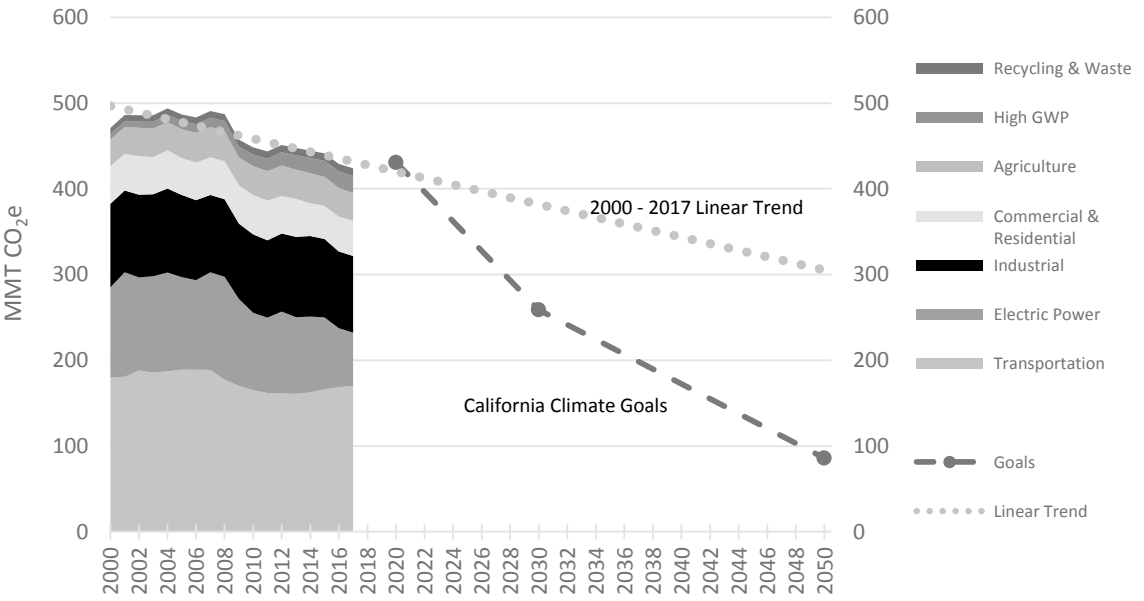

Fig. 1.4 California GHG emissions 2000-2017, linear trend to 2050, and climate goals. Data from CARB (2019)

the single largest market for automobiles in the U.S., California's standards became the de facto national standards, as automakers all retooled their production lines to meet these higher standards. However, in 2019, the Trump administration announced that it would revoke California's exemption. 
All of these sector-specific measures have been key to accelerating the process to advance a net-zero emission future for the State.

\section{California ETS}

As the primary economy-wide climate policy in the State, the California ETS augments the successes of sector-specific policies. The most recent revisions to the California ETS expand its legal mandate horizon to 2030 and increase climate ambition by now aiming at an emission reduction target of $40 \%$ below 1990 levels. California's carbon market is at the center of a comprehensive, well-integrated set of programs launched to achieve carbon neutrality by 2045 across key sectors of the economy. One contingent consideration is that the State legislature will need to reauthorize the cap-and-trade program to provide continuity beyond 2030 . So far, one of its strengths has been trans-administrational political commitment continuity across three governors from different political parties and legislature control by different parties across time. This continuous support has signaled a strong credible commitment to climate action, in particular the carbon market, to all stakeholders and economic agents in California and elsewhere. Californians in general support strong climate action. It also demonstrates to the rest of the world that you can decouple economic growth from GHG emission growth. As shown in Fig. 1.4, mid-century carbon neutrality goals are set across different sectors of the economy.

The carbon market aims to facilitate the State's GHG emission reduction goals by establishing a strict overall emission limit (i.e., cap) that decreases each year, while providing program participants with flexibility in their mitigation approaches. The agency in charge of regulatory enforcement and administration of this program is the California Air Resources Board (CARB), a very powerful and independent regulatory body. As described by CARB, the Cap-and-Trade Program is fundamental to meeting California's long-range climate targets at low cost. The CA ETS covers GHG emissions from transportation, electricity, industrial, agricultural, waste, and residential and commercial sources, and caps them while complementing the other measures needed to meet the 2030 GHG target.

The key policy design lessons derived from this implementation to date are as follows:

(1) A well-defined annual cap that declines annually ensures market stability and investor certainty.

(2) Robust measurement/monitoring, reporting and verification systems (MRV) based on accurate emission data ensures effective tracking of compliance and market function.

(3) Auctions and a hybrid price collar system (i.e., price floor, akin to a carbon tax when market prices are low, and a price ceiling, akin to a carbon subsidy when market prices are high) address potential market volatility. 
(4) A strong regulatory link with existing air quality standards for criteria (e.g., NOx, SOx, and volatile organic components) and toxic air pollutants protects against increases in distributional inequities in GHG co-pollutant exposures as a result of the ETS, supported by strong default penalties under the State's health and safety code.

(5) High penalties for non-compliance.

\section{Additional supplementary considerations}

Climate Investment Program and Equity: The revenue generated by auctions of allowances from the California ETS provides direct financial benefits to electricity rate payers (i.e., climate rebate), but more importantly funds low-carbon investment projects. As of March 2020, California's climate investments totalled $\$ 12.7$ billion dollars, supporting among other projects energy-efficient affordable housing, zeroemission vehicles and transport infrastructure (e.g., high-speed rail), and land use and urban forest initiatives. A key element of such climate investment fund is to provide solutions and benefits to disadvantaged and low-income communities. So far, $\$ 3.5$ billion has been allocated to benefit priority populations (CARB 2020).

Market Supervision: There is a market advisory committee supported by leading academics and environmental finance experts that assesses market performance. However, CARB has acquired its own internal capacity through staff to independently verify and assess potential market manipulation and the overall market performance of its cap-and-trade system.

Equity, Access, and Environmental Justice: It is important to devise environmental justice safeguards and compensatory programs to protect disadvantaged communities from the harmful effects to human health and welfare of localized exposures to GHG co-pollutants (criteria pollutants) emitted by facilities participating in the ETS and other pricing mechanisms. A quarter of the climate investment revenue goes to address the needs of disadvantaged communities. CARB's Environmental Justice Advisory Committee has also submitted recommendations for CARB to implement AB 197 which requires prioritizing emission reductions at the largest GHG sources and those specifically in disadvantaged communities. AB 197 also requires consideration of the social cost of GHG emissions, which includes the public health costs of GHG co-pollutants.

Linking: From the start, California made sure that the system to be implemented would be robust enough to meet its intended goals. CARB actually delayed its original start date to make sure that that was the case. As part of its international cooperation activities, it has advised many countries and regions around the world. There are four legal requirements for linking market-based mechanisms with other jurisdictions, as follows:

1. The jurisdiction with which the state agency proposes to link has adopted equivalent or stricter program requirements for greenhouse gas reductions, including, but not limited to, offset requirements. 
2. Under the proposed linkage, the State of California is able to enforce statutes against any entity subject to regulation under those statutes and against any entity located within the linking jurisdiction to the maximum extent permitted under the United States and California Constitutions.

3. The proposed linkage provides for the enforcement of applicable laws by the state agency or by the linking jurisdiction of program requirements that are equivalent to or stricter than those required by California law.

4. The proposed linkage and any related participation of the State of California in the Western Climate Initiative shall not impose any significant liability on the state or any state agency for any failure associated with the linkage.

Climate action in California constitutes a comprehensive, holistic approach to achieve ambitious GHG emission reduction goals in order to reach mid-century carbon neutrality goals across different sectors of the economy. Central among a suite of complementary policies, carbon pricing in the form of a cap-and-trade system is helping minimize the costs of advancing toward a smarter, innovative, clean economy model. The California ETS is an economy-wide program, setting a limit on approximately 85 percent of the state's GHG emissions. It complements and buttresses sectoral polices such as RPS and the LCFS. Clean technological innovation, resource efficiency, and cost-effective emission reductions are central to making a net-zero carbon California a reality by mid-century. As in the case of the EU ETS, California requires continuous adaptive management of its cap-and-trade system as part of a portfolio approach to sustain cost-effective carbon mitigation efforts, while delivering other co-benefits to its residents to underpin a prosperous, healthy, and climate-resilient future to communities across the state.

\section{Mexico}

For decades now, Mexico has been following and learning from the international experience designing and implementing ETS through its participation in the UNFCCC, G20, OECD, and other multilateral organization support groups like the Work Bank Program for Market Preparedness (PMR). The General Law of Climate Change (LGCC) of 2012, listed the concept of an ETS as a possible approach to reduce carbon emissions in order to achieve national climate policy goals, but without legally mandating its implementation. The need to reform the LGCC to align it with the Paris Agreement became clear after the participation of a group of key Mexican legislators in the Mexican delegation to the UNFCCC COP 23 in November 2017 and internal GOM and expert consultations at the summit. On December 12, 2017, the chamber of deputies sent its proposed amendments to the senate. Among these, the reforms to Article 94 mandated the implementation of an ETS and assigned authority to the Ministry of Environmental and Natural Resources (SEMARNAT). The law was ultimately passed in July 2018. An important aspect of these amendments to the LGCC is their emphasis on establishing a "consultation and representation" mechanism for 
ETS participating industrial sectors. Also, like past experiences in California and the EU, the ETS will include "progressive and gradual implementation" and minimize competitiveness impacts to industry vis-à-vis international markets. The same month, a new president was elected in the country. The new administration, with some delays and revisions, pushed forward with the pilot ETS (LGCC 2018).

\section{The Mexican ETS: From Learning-Phase to Compliance Mechanism}

On January 10, 2019, SEMARNAT published the agreement to establish the preliminary basis for the implementation of a "test" period for the Mexican ETS, toward developing a formal operational phase as per Article 94 of the LGCC. The program is being developed based on historical emission data (2016-2019) provided to the National Emissions Registry (RENE). In the last few years, the government has launched an effort to improve reporting and true-up reported emissions. The agreement establishes an emissions cap, a transactions tracking system of emission allowances and offsets (the exchange market), and introduces flexible compliance mechanisms (e.g., offsets). The 3-year learning phase has two periods: (1) From January 1, 2020, through December 31, 2022, and (2) the last year, 2022, which will be a transition toward the operational phase or compliance system where accurate reporting will be demanded by regulators. The objectives of the pilot period are to.

- Advance the achievement of Mexico's emission reduction goals;

- Promote emission reductions at the lowest cost possible in a measurable, reportable, and verifiable manner;

- Test the functioning of the ETS in the Mexican context, and educate participating sectors while developing the internal institutional capacity building for its successful implementation;

- Identify areas of improvement to fine-tune the system toward its operational phase;

- Generate robust and high-quality information;

- Create value for the emission permits and the compensation credits.

In this stage, no economic penalties will be imposed and allocations will be granted free and independent of reserve allowances.

Program scope: The Mexican ETS is not an economy-wide system, it includes only the industrial and energy sectors outlined as follows.

Energy Sector:

- exploitation, production, transport, and distribution of hydrocarbons; and

- the generation, transmission, and distribution of electricity.

Industrial Sector:

- Automotive;

- Cement; 
- Chemical;

- Food and beverages;

- Glass;

- Steel;

- Metallurgic;

- Mining;

- Petrochemical;

- Pulp and paper;

- Other subsectors that emit direct GHG from fixed sources.

Participation threshold: $100,000 \mathrm{tCO}_{2}$ or above of direct GHG emissions in any of the years between 2016 and 2019. All facilities reaching this emission level will have to participate for the duration of the pilot period, independently of reaching lower emission levels at some point during the implementation of the program.

Program participants: 300 facilities that represent more than $90 \%$ of the total emissions reported to RENE.

Regulated substance: Direct $\mathrm{CO}_{2}$ emissions from fixed sources as part of industrial processes and fuel burning in preparation for the compliance and operational phase of the program. Other gases and components with carbon equivalent properties will not be included during the pilot period.

Reserve: SEMARNAT can transfer credits from the general reserve to new entrants and those with increases in emissions because of expansion in production to maintain the "environmental integrity" of the program. (Art 21).

New entrants: Facilities that reach the $100,000 \mathrm{tCO}_{2}$ threshold and above starting in 2020 and beyond.

Auctions: Can be used at the start of the second year of the learning phase derived from the allowances deposited in the reserve contingent on the ETS market performance.

Reconciliation period: On 1 November of each calendar year, participants and new entrants to the program will have to hold a number of credits equivalent to the emissions reported from the immediate previous year and verified according to a preestablished submission schedule for the pilot period (i.e., Annex 1 of the market rules). On-time and fully compliant reporting will allow participants to trade excess allowances in their accounts or to be used to comply with future requirements within the test period. Those failing to submit on time and not remaining fully compliant before 15 November of this account reconciliation period will not be able to trade allowances, and each excess allowance in this stage will be discounted at a double rate ( 2 for each non-compliant allowance) during the first allocation at the start of the operational phase of Mexican ETS compliance. All allowances issued for the pilot period will be canceled at the end of 2023 . 
Facility retirement: If a fixed source is permanently closed, the allowances allocated to such facility will be returned to SEMARNAT and will follow a preset schedule and proportional return depending on the date of the closure. These allowances will be retired from the program.

Market transactions: These operations will be conducted among program participants through the tracking system and exchange platform of the Mexican ETS. They will only be considered fully executed if they are registered in the aforementioned tracking system.

Market supervision: SEMARNAT will maintain the environmental integrity of the system by setting maximum amounts of allowances to be purchased per participant. If allowance hoarding, market manipulation, and perceived monopolistic behavior are detected in accordance with the Federal Law of Economic Competition, it will inform the corresponding agency (i.e., Federal Commission of Economic Competition) to take legal action against such actors.

Electronic Exchange Platform: The Mexican ETS is expected to provide an electronic system to issue, transact, and cancel allowances and compensatory credits (e.g., offsets). It will provide a means to account for valid allowances and compensatory credits as part of the systems and to create a directory of registered program participants and their accounts. This electronic system will make it possible to validate and register all transactions as well as the regulatory action taken by SEMARNAT, such as:

- Allocation;

- Buying and selling;

- Acquisitions through auctions;

- Compliance allowance submissions;

- Cancelation of allowances;

- Maintenance throughout compliance periods (preset schedule);

- Creating and keeping up accounts;

- Registering the number of emission products for the verification process.

In short, the Mexican ETS platform will be the repository of transactions, accounts, and all aspects relevant to its operation while following legal transparency requirements regarding public information and the protection of participants' confidential information.

Precautionary Measures: If SEMARNAT detects activity contrary to the environmental integrity of the system, such as gaming or intervening in the system, or abusing the ETS by any other means, it will suspend culprit accounts. Accounts will have 15 days to clarify actions and SEMARNAT will then decide on the continuation of suspension or restoring account rights.

As for crediting, clarification is required in terms of early action and compensatory measures. An important element of the learning phase is the information derived from the actual implementation experience. Article 10 requires comprehensive reporting regarding. 
- Price behavior;

- Emission reductions achieved;

- Percentage of emissions that account for total national emissions;

- Actual administrative costs as well as the operational costs of the tracking systems.

Based on this information and fine-tuning of the system, SEMARNAT and the Mexican ETS Advisory Committee will review the achievements of the pilot period and progress toward meeting national emission reduction goals. Analytical support from the National Institute of Climate Change (INECC) should supplement this review. In particular, these institutions will evaluate the potential to achieve additional emission reductions, the benefits to the population in general and to program participants, mitigation costs, and the administrative and MRV functioning of the program. Additionally, from the start, some industries, for instance, cement, were very concerned about the advantages and disadvantages vis-à-vis non-participating facilities and public information requirements. Moreover, the assessment of the pilot period is expected to include an analysis of the impact of the ETS on other GHG mitigation policy instruments in Mexico's climate action plan. Finally, the assessment process will evaluate if new sectors of the economy should be covered under the Mexican ETS.

\section{Implementation Challenges Ahead}

The pilot phase of the Mexico ETS will inform the operational compliance phase. Challenges remain ahead, and exogenous factors threaten its full-fledged implementation as a flexible, cost-effective compliance mechanism. These range from political risk and funding to institutional capacity and technical aspects such as highquality information on emission and transparency measures. Some of these include the following.

Budget Shortfalls and Policy Continuity Risk: The Obrador Administration's planned "budget savings" and the process of shrinking of government agencies, along with the expected impact of the COVID19 global health crisis on the economy, will further limit the resources available for environmental protection in Mexico. Moreover, the ongoing institutional reorganization of SEMARNAT and the changes in leadership at the helm of the agency, including three ministerial appointments since December 2018, threaten policy commitment and continuity for this policy approach. The Mexican ETS does require some key immediate investments that will face budgetary constraints, such as hiring staff with appropriate expertise at SEMARNAT and setting up the electronic platform for the program. The IT systems of the Mexican ETS will also have to invest in cybersecurity safeguards and other emerging solutions such as blockchain, as they mature.

Institutional Frameworks and Inter-Agency Coordination: SEMARNAT will also have to develop methodologies to assess the environmental integrity of the ETS and its key components, for instance, in the case of compensatory measures and 
the offset system to provide additive cost containment mechanisms to emitters. This includes policy alignment with the existing carbon tax, which will require a high degree of inter-agency cooperation and collaboration, for instance, with the Ministry of Finance and the National Forestry Commission. It will also require open consultation processes with stakeholders to developing the appropriate institutions to sustain carbon pricing revenue, environmental commodities trading, and climate investment mechanisms. Mexico has great potential to develop natural climate solutions (NCS) or nature-based solutions (NBS) through agricultural, forestry, and other land uses (AFOLU) as a means to conserve natural capital and support communities in these areas. This in turn will require collaboration with the communities potentially hosting these projects, capacity building, legal certainty, and strong institutional and political support for the creation of such environmental financial products. Additionally, NCS will require clarification vis-à-vis NDCs to avoid double counting. The Ministry of Energy is no longer prioritizing decarbonization of the sector and deployment of clean energy at this time. Policy-constructive engagement from energy regulators is key to effective climate action.

Inventory and MRV systems: The process of improving the quality of the information provided to the emissions registry (i.e., RENE) should continue. Also, there is room for improvement on regulatory emission reporting procedures, as the conventional Environmental Certificate of Operation (COA) and $\mathrm{CO}_{2}$ direct emission reporting may be too burdensome in addition to the GHG monitoring plans. Thus, there is an opportunity to harmonize and streamline the reporting system. RENE's data is critical to setting a transparent, stringent cap. MRV errors may result in overallocation of allowances at the start of the compliance phase. The new industry of GHG certification entities is working on adapting their services to provide more seamless reporting products to regulated entities.

Mexico has the opportunity to deepen its collaborative work with the rest of the Americas in expanding carbon pricing, markets, and clean innovation opportunities. It has been working, for instance, with Colombia and Chile. Looking north, California has already served as a blueprint for the Mexican ETS and continues to regularly advise and provide technical assistance. This is important. Aspiring to meet the highest standards in the design and implementation of national ETS around the world can foster certainty, integrity, and credibility in the implementation path of a workable and cost-effective global carbon market. Getting it right from the start in the implementation of the Mexican ETS will no doubt contribute toward the institutional build-up of the North American carbon market as a major step toward the development of a global system. This will demonstrate that it is possible to align accounting and policy designs between developed and developing nations. Mexico, like California, Quebec, and the European Union, is a responsible actor contributing to the global effort to stabilize the accumulation of GHG emissions in our atmosphere. The Mexican government should also aim to maximize the low-carbon development opportunities that the transition to a cleaner, more resource-efficient economy presents. That process is being put on hold because of new directions in Mexico's federal energy policy. A resource-efficient nation is a more competitive 
one. Energy policy is climate policy. Alignment and coordination between resource, energy, and environmental federal policy goals are sorely needed.

\section{Concluding Remarks}

The road ahead for the implementation of the Mexican ETS is a rocky one. There is a high level of political risk given current uncertainties in the disconnect between energy and climate policy in Mexico. The UNFCCC still has to clarify important aspects of Article 6 of the Paris Agreement. To succeed, policy continuity and fullinstitutional endorsement of this policy approach at the federal level must be achieved during the transition between the learning phase and the ETS operational compliance. This would signal a credible commitment from the federal government to the Mexican carbon market. A well-integrated, workable cap-and-trade system for carbon in Mexico will take into account the idiosyncrasies of the Mexican implementation context that will emerge from its learning phase, but should also aim to implement the highest international policy design standards for its compliance phase to ensure future connectivity and linking with international markets.

Gradual ratcheting up of ambition for cost-effective carbon mitigation, strong accounting standards, and MRV measures, using auctions and revenue proceeds for climate investment and clean innovation, along with strong penalties for noncompliance are central to the economic and environmental performance of an ETS. These objectives need to be balanced with other national policy objectives for a more prosperous, just, and clean economy in Mexico. The U.N. SDGs provide an array of examples on how to achieve this in a sustainable manner. Moreover, linking the ETS and offset mechanisms with strong regulations on GHG-co-pollutants which effect public health will be key to avoiding growing disparities in exposures across the country (i.e., environment justice). Additionally, care needs to be taken in the design of any offset program in the country. NCS projects' social dimension consideration is important, for instance, and should be designed in close partnership with the communities conserving Mexico's natural capital assets to ensure they are equal negotiators in these projects and they benefit from these climate investment flows. On the other hand, Mexico will have to work on providing legal certainty, institutional support, and permanence to such environmental products.

Getting it right from the start of the compliance period based on the pilot period experience is important. Periodically fine-tuning the system based on new scientific, technical, and accumulated implementation experience domestically, as well as from other carbon market developments from around the world, will be necessary. As pointed out above, the necessary interactions between social, institutional, and political forces bear on the quality of an emissions trading mechanism's design (Perez Henriquez 2013). Regulators will need to remain vigilant in the transition to the operational phase of the Mexican ETS, particularly by avoiding the granting of too many political concessions to all regulated entities or by not considering interaction with other governmental policies and measures that would reduce the environmental 
integrity and the overall cost-effectiveness of the program. A high degree of institutional coordination and alignment is needed within government agencies to prepare Mexico for the new clean economy. Ultimately, uncoordinated decision-making tends to result in resource use that is socially inefficient.

\section{References}

Baumol WJ, Oates WE (1988) The theory of environmental policy. Cambridge University Press

Burke M, Craxton M, Kolstad CD, Onda C, Allcott H, Baker E, Barrage L, Carson R, Gillingham $\mathrm{K}$, Graff-Zivin J, Greenstone M (2016) Opportunities for advances in climate change economics. Sci 352(6283):292-293

California Air Resources Board (CARB) (2017) Climate change scoping plan: the strategy for achieving California's 2030 greenhouse gas target

California Air Resources Board (CARB) (2019) California Greenhouse gas 2000-2017 emissions trends and indicators report

California Air Resources Board (CARB) (2020) Cap-and-trade auction proceeds: annual report to the legislature

Climate Action Network (2019) COP25. Eco-NGO Newsletter. Winter 2019. Madrid, Spain

Coase R (1960) The problem of social cost. J Law Econ 3(1):1-44

Crocker T (1966) Structuring of atmospheric pollution control systems. In: Wolozin H (ed) The economics of air pollution. W.W. Norton, New York

Dale JH (1968) Pollution, property, and prices: an essay in policy-making. University of Toronto Press, Toronto

Delbeke J, Vis, P (eds) (2019) Towards a climate-neutral Europe: curbing the trend. Routledge

Dietz S, Stern N (2008) Why economic analysis supports strong action on climate change: a response to the Stern Review's critics. Rev Environ Econ Policy 2(1):94-113

Edmonds J, Forrister D, Clarke L, de Clara S, Munnings C (2019) The economic potential of article 6 of the Paris Agreement and implementation challenges. International Emissions Trading Association, University of Maryland, and Carbon Pricing Leadership Coalition, Washington, D.C.. World Bank. Retrieved from: https://openknowledge.worldbank.org/handle/10986/33523 License: CC BY 3.0 IGO

European Commission (2020) Environmental taxes in the EU. Eurostat, statistics explained. January 2020. Retrieved from: https://ec.europa.eu/eurostat/statistics-explained/index.php/Environme ntal_tax_statistics\#Environmental_taxes_in_the_EU

European Commission (2017) Emissions trading system (EU ETS) revision for phase 4 (20212030). Retrieved from: https://ec.europa.eu/clima/policies/ets/revision_en

Gibbens S (2019) 15 ways the Trump administration has changed environmental policies. National Geographic. Retrieved from: https://www.nationalgeographic.com/environment/2019/02/15ways-trump-administration-impacted-environment/

Gillingham K (2019) Carbon calculus: for deep greenhouse gas emission reductions, a long-term perspective on costs is essential. Financ Dev 56(004)

Goulder LH (1995) Environmental taxation and the double dividend: a reader's guide. Int Tax Public finance 2(2):157-183

Goulder L, Parry I (2008) Instrument choice in environmental policy. Rev Environ Econ Policy 2(2): $152-174$

Hahn RW, Stavins RN (1992) Economic incentives for environmental protection: integrating theory and practice. Am Econ Rev 82(2):464-468

Hanemann WM (1994) Valuing the environment through contingent valuation. J Econ Perspect $8(4): 19-43$ 
Hanley N, Shogren JF, White B (2016) Environmental economics: in theory and practice. Macmillan international higher education

International Carbon Action Partnership (ICAP) (2020) Emissions trading worldwide: status report 2020. International Carbon Action Partnership. Berlin, Germany. Retrieved from: https://icapca rbonaction.com/en/icap-status-report-2020

Intergovernmental Panel on Climate Change (IPCC) (2007) Summary for policymakers. In: Solomon S, Qin D, Manning M, Chen Z, Marquis M, Averyt KB, Tignor M, Miller HL (eds) Climate change 2007: the physical science basis. Contribution of working group I to the fourth assessment report of the intergovernmental panel on climate change. Cambridge University Press, Cambridge, United Kingdom and New York, NY, USA

Jackson RB, Friedlingstein P, Andrew RM Canadell JG, Le Quéré C, Peters GP (2019) Persistent fossil fuel growth threatens the Paris agreement and planetary health. Environ Res Lett 14(12): 121001

Newell RG, Stavins RN (2003) Cost heterogeneity and the potential savings from market-based policies. J Regul Econ 23:43-59

Nordhaus WD (2017) Revisiting the social cost of carbon. Proc Natl Acad Sci 114(7):1518-1523

Nordhaus, W.D. (2005). Life after Kyoto: alternative approaches to global warming. National Bureau of Economic Research (NBER) Working Papers, (11889)

Parry IW, Mylonas V (2017) Canada's Carbon Price Floor. Nat Tax J 70(4):879-900

Pérez Henríquez B (2004). Information technologies the unsung hero of environmental markets. Resources Fall/Winter, 9-12

Pérez Henríquez B (2013) Environmental commodities markets, towards a low carbon future. Resource for the Future Press, Washington, DC.

Pigou AC (1932) The economics of welfare, 4th edn. Macmillan and Co., London

Pizer W (1999) Optimal choice of policy instrument and stringency under uncertainty: the case of climate change. Resour Energy Econ 21:255-287

Schmalensee R, Stavins R (2017) Lessons learned from three decades of experience with cap and trade. Rev Environ Econ Policy 11(1):59-79

Secretaría de Medio Ambiente y Recursos Naturales (SEMARNAT) (2019) Acuerdo por el que establecen las bases prelimnares del Programa de Prueba de Sistema de Comercio de Emisiones. Diario Oficial de la Federación: México, Enero 10, 2019. Retrieved from: https://www.dof.gob. $\mathrm{mx} /$ nota_detalle.php?codigo $=5573934 \&$ fecha $=01 / 10 / 2019$

Stavins R (2018) What should we maker of China's announcement of a national $\mathrm{CO}_{2}$ trading system. An economic view of the environment a blog by robert stavins. Retrieved from: http://www.rob ertstavinsblog.org/2018/01/07/make-chinas-announcement-national-co2-trading-system/

Stern N (2007) The economics of climate change: the stern review. Cambridge University Press, Cambridge

Teixidó J, Verde SF, Nicolli F (2019) The impact of the EU emissions trading system on low-carbon technological change: The empirical evidence. Ecol Econ 164:106347

Tietenberg TH (2005) Tradable permits in principle and practice. Penn St Envtl L Rev 14:251

Tietenberg TH (2006) Emissions trading: principles and practice. Resources for the Future (RFF Press), Washington, D.C

United Nations Conference on Trade and Development (UNCTAD) (1997) Greenhouse gas emissions trading on the global climate agenda. Retrieved from: https://unctad.org/en/Pages/PressR eleaseArchive.aspx?ReferenceDocId=3277

United States Agency for International Development (USAID) (2017) Climate change risk profile for Mexico. Retrieved from: https://www.climatelinks.org/resources/climate-change-risk-pro file-mexico

United States Energy Information Administration (USEIA) (2020a) Data dashboard. https://www. eia.gov/beta/states/data/dashboard/renewables

United States Energy Information Administration (USEIA) (2020b) State energy data system. https://www.eia.gov/state/seds/sep_sum/html/xls/use_es_capita.xlsx 
United Nations World Commission on Environment and Development (UNWCED) (1987) Report of the world commission on environment and development: our common future. United Nations General Assembly Document A/42/427

Willsher K (2018) Gilets Jaunes protesters threaten to bring France to a standstill. The Guardian, Nov 16, 2018. Retrieved from: https://www.theguardian.com/world/2018/nov/16/gilet-jaunesyellow-jackets-protesters-france-standstill

World Bank (2015) Escalating call to put a price on carbon. Retrieved from: https://www.worldb ank.org/en/news/feature/2015/12/01/escalating-calls-to-put-a-price-on-carbon

World Bank (2020) Carbon pricing dashboard. Retrieved from: https://carbonpricingdashboard. worldbank.org/map_data

Open Access This chapter is licensed under the terms of the Creative Commons Attribution 4.0 International License (http://creativecommons.org/licenses/by/4.0/), which permits use, sharing, adaptation, distribution and reproduction in any medium or format, as long as you give appropriate credit to the original author(s) and the source, provide a link to the Creative Commons license and indicate if changes were made.

The images or other third party material in this chapter are included in the chapter's Creative Commons license, unless indicated otherwise in a credit line to the material. If material is not included in the chapter's Creative Commons license and your intended use is not permitted by statutory regulation or exceeds the permitted use, you will need to obtain permission directly from the copyright holder. 